\title{
On the Strategies of Graduation Thesis Writing Teaching of Translation Major Undergraduates Based on Eco-Translatology
}

\author{
Wang $\operatorname{Lin}^{1,2}$ \\ ${ }^{1}$ School of Foreign Languages and Literature, Wuhan University, Wuhan, China \\ ${ }^{2}$ School of Foreign Languages, Leshan Normal University, Leshan, China \\ Correspondence: Wang Lin, School of Foreign Languages and Literature, Wuhan University, Wuhan, China; \\ School of Foreign Languages, Leshan Normal University, Leshan, China. Tel: 13880484919. \\ E-mail:w_lin832@163.com
}

Received: June 20, 2017 Accepted: July 8, $2017 \quad$ Online Published: July 10, 2017

doi: 10.5539/elt.v10n8p63 URL: http://doi.org/10.5539/elt.v10n8p63

\begin{abstract}
Graduation thesis is an indispensible procedure for each undergraduate, which is crucial for successful graduation, employment, further study and even further development. However, due to most undergraduates' ignorance of academic writing and the deficiency of current thesis writing course, thesis writing ability can hardly be enhanced and improved, accordingly, few good graduation theses can be produced among undergraduates. As a newly-launched major in recent a few years, translation major (BTI education, i.e. Bachelor of Translation and Interpretation) is also faced up with this problem. Eco-Translatology, a new theory combining ecology and translation studies, holds translation as adaptation and selection, which can also provide important enlightenment for thesis writing of translation majors. This paper, based on Eco-Translatology and current thesis writing course deficiency, aims to explore constructive strategies on how to give effective and efficient thesis writing course in hope of greatly improving thesis writing.
\end{abstract}

Keywords: course of thesis writing, strategy, translation major, Eco-Translatology

\section{Introduction}

With the great development of undergraduate education in China in recent years, there come out more and more undergraduates each year. Accordingly, their graduation theses have become a prominent problem which cannot be overlooked in the process of undergraduate education, since the thesis is closely related to the quality of translation major. Generally speaking, the quality of undergraduates' theses is far from satisfaction in most aspects. Therefore, besides the element of students' respective supervisor, the course of graduation thesis writing is quite important. The exploration into effective and efficient strategies in thesis writing teaching is essential and worthwhile, since students mainly acquire knowledge about academic writing in classroom.

\section{Literature Review}

Recently, there are a few scholars having done relative researches on undergraduates' thesis writing, but they focus on English major only (Guo, 2004; Kong, 2010; Chen et al., 2015; Li \& Zhang, 2015). However, since the launch of translation major (BTI education, i.e. Bachelor of Translation and Interpretation) for undergraduates in 2006, there are more and more undergraduates in such a major. Different from English major, translation major owns its distinctive components such as training goal, teaching requirements, orientation and curriculum assignments. But according to the author's search, there are few papers talking about the course of graduation thesis writing of translation major (the newly-launched major). There are merely some scholars talking about thesis writing and thesis defense of translation major. Xie talks about problems in thesis defense of translation major (Xie \& Li, 2012). Hou talks about the combination of thesis writing of translation degree program with translation market (Hou, 2013). Zhuo talks about the exploration into graduation thesis of translation direction in English major (Zhuo, 2016). However, there must be an issue having priority over thesis writing or thesis defense, that is, how a teacher arrange the thesis writing course in an effective and efficient way. This paper, based on the analysis of current thesis writing course of translation major, aims to explore constructive teaching strategies directed against graduation thesis writing of translation major from the perspective of adaptation and selection in Eco-Translatology, which is of great significance and necessity. 


\section{Current Situation of Thesis Writing Course of Translation Major}

The Teaching Requirements for BTI Education formulated by China National Committee for BTI Education has clearly stipulated the requirements for graduation thesis for BTI in 2012. According to the teaching instruction document (2012), there are two forms for BTI graduation thesis- a research thesis in a traditional way and a practice report on translation. Additionally, some new professional requirements have been added in this document. However, the teaching of thesis writing for BTI is still with some problems.

\subsection{Following the Traditional Model of Thesis Writing Teaching of English Major}

As mentioned above, translation major (Bachelor of Translation and Interpretation) is a newly-launched major in China, concentrating on students' practical abilities of written translation and oral interpretation. However, some teachers still follow the traditional model of thesis writing teaching designed for English major without paying enough attention to the distinction between the two majors. They still expound the way to write graduation thesis from the five aspects, i.e. American and British Literature, General Linguistics, Western Culture, English Pedagogy and Translation between English and Chinese. Accordingly, here comes another problem, that is, a large number of students choose to write research thesis about translation without consideration of practice report on translation. Obviously, it is inappropriate to focus unduly on literature, linguistics, culture and English pedagogy when doing thesis writing teaching for translation majors

\subsection{Ignoring General Knowledge about Academic Writing in Thesis Writing}

Generally speaking, a bachelor's degree thesis is not so demanding as a master dissertation in terms of academic originality and theoretical construction. Therefore, the instruction of format and language expression only is very likely to be stressed in class. However, general knowledge about academic research and academic writing must be taught because they are more important than format and expression in thesis writing for both students' academic research as beginners at present and their further study in postgraduate stage.

\subsection{Ignoring Specific Theoretical Supervision}

Generally speaking, a theoretical framework is needed in a research thesis and a practice report on translation since it functions as a basis and guide for a degree thesis, which most undergraduates are not so familiar with. However, due to various reasons such as limited time for class, teachers' limitation on some certain theoretical knowledge and students' boredom towards theory acquisition, such specific theories are not adequately elaborated in class. Accordingly, the theoretical framework cannot function well in students' theses.

\subsection{Lack of Professional Teachers in the Industry}

As is known, translation is an activity full of practice, so is the graduation thesis writing of translation major whether the research thesis about translation or the practice report on translation. However, according to the author's interview and investigation, in most schools of foreign languages of universities or colleges most full-time teachers (from the department of translation major or English major) are arranged to teach the course of thesis writing without taking consideration of some part-time teachers such as professional translators, interpreters or project managers from translation associations or translation companies.

\subsection{Lack of Integration of Various Subjects}

Thesis writing involves many relative subjects rather than thesis writing course only, and it is also the case with the thesis writing course of translation major. According to the investigation, the thesis writing course is taught by only one teacher (mostly with academic background of a certain subject in English language) during the whole semester in the majority universities or colleges, which can hardly produce effective integration among different subjects in translation research.

\section{Eco-Translatology and Thesis Writing in Translation Major}

Eco-Translatology proposed by Hu Gengshen innovatively combines ecology with translation research, and it is taken as translation research from the perspective of ecology on the one hand and a branch under general translation research on the other hand. According to Eco-Translatology (Hu, 2013), translation is taken as adaptation and selection in the environment of texts and translation community involving translator, readers, source culture and target culture. In other words, translators should try their best to make translating process adapt to the language environment, and accordingly selections made in this process are out of the language environment.

In fact, the enlightenment provided by adaptation and selection in Eco-Translatology is important. It is also the case for thesis writing. Firstly, thesis writing generally aims at solving a certain problem in a field, which is the same as the function of translation. Thus, thesis writing must adapt to the variety of problems in people's daily 
life. Secondly, thesis writing, like translating, is a process filled with the author's (translator's) selection, thus the selection should conform to the requirements of a certain application field. Thirdly, due to the features of translation major, thesis writing of translation majors must involve more or less translating work, so that the work of creatively thesis writing and materials or examples translating should be done by the same person - the author of the thesis. To sum up, thesis writing, especially that of the translation major, is influenced by adaptation and selection, therefore, it is feasible to do researches on the teaching of graduation thesis writing of translation major under the guidance of Eco-Translatology.

\section{A Comparison between Thesis Writing in English Major and that in Translation Major}

Generally speaking, both teachers' and students' failure to effectively distinguish translation major thesis from traditional English major thesis largely accounts for not clearly knowing distinctive features in translation major thesis. Due to its own training goal, teaching requirements, orientation and curriculum assignments, the graduation thesis of translation major is accordingly distinctive from that of English major in terms of forms, styles, requirements, research object, research perspective and other aspects. Thus, it is necessary for teachers and their students to know differences between thesis writing in English major and thesis writing in translation major, and this is also a key point in thesis writing course.

Table 1. A comparison between thesis writing in English and thesis writing in translation major

\begin{tabular}{ll}
\hline English Major & Translation Major \\
\hline $\begin{array}{l}\text { Focusing on linguistics, literature, culture, pedagogy } \\
\text { and translation }\end{array}$ & $\begin{array}{l}\text { Focusing on translation theory and translation practice } \\
\text { only } \\
\text { Giving priority to fundamental research } \\
\text { Research paper }\end{array}$ \\
Mainly about secondary research for students & $\begin{array}{l}\text { Research paper + Practice report } \\
\text { Either secondary research or primary research for } \\
\text { students } \\
\text { Less closely related to other disciplines } \\
\begin{array}{l}\text { Mainly from the research perspective of English } \\
\text { language theory }\end{array}\end{array}$ \\
\hline
\end{tabular}

From the table, we can easily find some prominent differences between graduation thesis of English major and that of translation major, based on which teachers are expected to adjust teaching of thesis writing for translation majors. According to the table, thesis of English major generally owns five academic directions including translation studies while thesis of translation major focuses on translation studies more accurately. Moreover, for undergraduates majoring in English, a majority of them are likely to do secondary research based on a certain literary or linguistic theory since it is relatively difficult for them to do primary research or empirical research under existing conditions (personal practical ability, personal cognition, equipment provided by university of college or lacking in cooperators on campus or off campus). However, undergraduates majoring in translation, due to the practical characteristic of the major, are more likely to try to do some primary researches or empirical researches, which add more elements of academic originality to thesis. Last but not the least, with the development of scientific technology and the research perspective turn of translation research, there is a tendency that translation research can be done from the perspectives of science, neurology, cognition, psychology, ecology and so on. Therefore, students majoring in translation can get in touch with disciplines other than English language and broaden their vision in the process of thesis writing. To sum up, the course of thesis writing for translation major cannot be given in the same way as that of English major. The course design must take the specific features of translation major thesis into account and conform to the development of undergraduates majoring in translation.

\section{Requirements of Translation Industry or Translation Market in Terms of Graduation Thesis Writing}

As is known to all, graduation thesis writing is an indispensible procedure involving both theory and practice in university or college education. What's more, graduation thesis writing is also an important stage in talents training, which is generally regarded as the most important function for a university or a college. Therefore, graduation thesis writing must take talents training and employment into consideration. As for translation major, its graduation thesis writing must take the requirements of translation industry or translation market into account. 
As for translation industry and translation market mentioned here, they mainly refer to information about translation as a profession, information about translation studies, information about translation as a service or business, information about translation as a strategy influencing various fields in the society nowadays. In this way, graduation thesis for translation majors means more than only a procedure for students to successfully graduate. To be specific, students can learn something practical about translation industry or translation market in the process of thesis writing (including title selection, literature search, and review, writing, translating or interpreting and so on), which can be used in their profession in the future, while translation industry or translation market can have an opportunity to absorb new excellent translators or interpreters through graduation thesis.

In view of the facts mentioned above and the prospect of translation major, the writing of graduation thesis of translation major must conform to the latest development of translation industry or translation market. First of all, the selection of titles should try to conform to the latest trends in translation studies. Secondly, thesis writing should try to include new findings in translation industry. Thirdly, thesis writing should take the needs of translation market into consideration.

\section{Constructive Strategies about Thesis Writing Teaching of Translation Majors Based on Adaptation and Selection}

Based on the theory of Eco-Translatology and the current situation of thesis writing course of translation major, this section proposes some strategies to optimize this course in order to improve its teaching effect to the utmost.

\subsection{Integrating Thesis Writing Teaching into Other Courses}

According to the author's investigation, the thesis writing course is mostly arranged once a week in the second half semester of the third year of translation majors. Frankly speaking, there are two problems. Firstly, it is late for students to get acquaintances with fundamentals about thesis writing in their junior stage. Secondly, it is far from enough to instruct students in thesis writing within such a limited duration especially for translation majors who should get to know different forms of graduation thesis. In view of this situation, there are two points suggested for consideration. Firstly, the thesis writing course can be properly added to twice a week so that students can learn more and practice more in class about translation research thesis and practice report on translation. Secondly, graduation thesis writing is a big task and it cannot be solved by thesis writing course only. Exactly speaking, all the professional courses of translation major related to thesis writing should contribute more or less to the acquisition of thesis writing such as Intensive Reading, Extensive Reading, Written Translation, Oral Interpretation, British and American Literature, and Translation Criticism and Appreciation. During such courses, teachers can tell students something fundamental about academic research like topic selection, academic norm, literature search and literature review. Additionally, teachers in charge of these courses can also choose term paper as the way of assessment at the end of a term, so that students can get in touch with academic writing in advance.

\subsection{Greatly Enriching Theory Instruction in Class}

For BTI education, teachers are expected to pay more attention to practice of written translation or oral interpretation with slight mention of translation strategies and skills, which also conforms to the training goal of BTI. However, students are apt to find it quite difficult to write graduation thesis since they know little about theory. However, with the development of all aspects of the society, there are more and more new theories or new perspectives coming in to academic research. Teachers should actively adapt to this change. Firstly, teachers are expected to enrich translation theories at home and abroad. Some main translation theories (eg. Skopos Theory, Relevance Translation Theory, Theory of Norms, Translation Ethics, Alike in Form, Beauty in Sense, in Sound, and in Form, Faithfulness, Expressiveness and Elegance etc.), well-known translators or translation theorist (eg. Eugene A. Nida, Susan Bassnett, James. S. Holmes etc.) and important translation schools (eg. School of Polysystem Theory, American Translation Workshop, Deconstructional School, Manipulation School etc.) can be introduced to students in class. Secondly, relative theories from other disciplines and other research perspectives can be introduced to students such as CAT (Computer Aided Translation), neurology, ecology, and anthropology. In this way, students can acquire some important theories and broaden their research perspectives, which can greatly facilitate procedures in thesis writing like the selection of title and the mastery of theoretical framework.

\subsection{Strenghening General Knowledge and Writing Practice of Academic Writing}

Nowadays, the protection of intellectual property rights is emphasized more intensively than ever before. Thus, the academic ethics and norms in thesis writing are more and more important, and thesis teaching should adapt to 
this trend. In thesis writing course, teachers are expected to strengthen two aspects and guarantee the balance between knowledge and practice. On the one hand, teachers should theoretically tell students detailed information about academic ethics and academic norms including no plagiarism, title setting, abstract, introduction, arrangement of structure, literature review, conclusion, bibliography, acknowledgements, letter of authorization, appendix and so on. On the other hand, teachers should arrange a certain number of periods for students' writing practice and assessment. Generally speaking, if students, under the guidance of teachers, can make full use of thesis writing class time for writing practice about introduction, abstract, literature review and conclusion, they may find it easy to write their graduation thesis later on.

\subsection{Paying Attention to Interpretation Research}

Due to difficulty in practical operation or lack of interpretation experience, students are hesitated to do research on interpretation. In other words, most theses are about written translation rather than oral interpretation. In fact, it is unreasonable since BTI includes both written translation and oral interpretation. Additionally, with the development of international exchange in most fields, interpretation is focused more and more frequently. In view of the situation above, teachers are expected to selectively tell students something theoretical about interpretation (Simultaneous Interpretation and Consecutive Interpretation) and encourage students to bravely participate interpretation activities. Moreover, students can write practice report on oral interpretation. Additionally, interpretation teachers are required to instruct students in some theories about interpretation along with practice instruction.

\subsection{Expanding the Teaching Staff for the Course of Thesis Writing}

As mentioned above, in most schools of foreign Languages of universities or colleges, full-time teachers majoring in English or in translation are mostly arranged to take responsibility for thesis writing course of translation major. However, written translation and oral interpretation are an activity full of practice, and consequently only full-time teachers majoring in English or in translation are not enough for this course because they are likely to lack translation experience of various practical materials (especially materials about medicine, science, biology, law, various business documents or contracts) on the one hand, and to know little about how to manage and implement an translation project. Therefore, some excellent professionals full of industry experience could be employed for thesis writing course of translation major. Such professionals can be professional translators or interpreters, project managers or directors of a translation company, experts of a translation association and so on, who themselves are indispensible members of the translation community in the translation ecosystem. The teaching model can be various and flexible. Firstly, the cooperation model of full-time teachers and part-time professionals can be adopted, and they can deal with respective sections of the course they are good at or familiar with. Secondly, full-time teachers are in charge of class teaching per week while professionals can be invited for some academic lectures or seminars focusing on some certain subjects related to translation major thesis writing. In this cooperative way, students can gain benefits theoretically and practically, thus the course of graduation thesis writing can have a good effect and so can the following thesis writing.

\subsection{Adding Information about Thesis Defense to the Course}

Most teachers in thesis writing course chiefly tell student how to write a thesis, which is generally regarded as the most important task in such a course. However, here comes another problem, which is likely to be ignored. Almost all the students know nothing about thesis defense. In fact, information about how to prepare for thesis defense, the strategies and skills in thesis defense and the way to do note-taking in thesis defense is also of great importance and necessity. It is good for students to know such information before thesis defense.

\section{Conclusion}

Graduation thesis writing is a very important procedure in the whole cultivation program of translation majors, which is a comprehensive examination about four-year learning and provides a basis for further study or further vocation in translation field. As a newly-launched major, the translation major is expected to explore a new model for the teaching of thesis writing so as to guarantee the quality and the specificity of graduation thesis of translation major. Eco-Translatology, translation theory as it is, provides important enlightenment for the teaching of thesis writing. On the one hand, much necessary and new information about translation must be added to thesis writing course in order to adapt to the development of disciplines; on the other hand, a cooperative model between teachers on campus and professionals or experts off campus can be constructed for the teaching of thesis writing in order to adapt to the requirements of translation industry and translation market. In this way, the course of graduation thesis writing of translation major undergraduates can be greatly optimized, thus the quality of translation undergraduates can be accordingly improved. 


\section{References}

Chen, T. et al. (2015). Classroom Teaching Strategies for Graduation Thesis Writing of English Major. Overseas English, 24, 68-69.

China National Committee for BTI Education. (2012). The Teaching Requirements for BTI Education. Beijing: Higher Education Press.

Guo, Q. (2004). On the Teaching of Graduation Thesis Writing of English Majors Based on Internet. Foreign Languages and Their Teaching, 10, 18-21.

Hou, Y. (2013). Combination of Thesis-Writing of Translation Degree Program with Translation Market. Foreign Language and Literature, S1, 161-162.

Hu, G. (2013). Eco-Translatology - Construction \& Interpretation. Beijing: The Commercial Press.

Kong, L. (2010). A Study in the Course of Writing English Research Papers-A Teaching Practice. Journal of Linyi Normal University, 2, 52-55.

Li, H., \& Zhang, C. (2015). On Practice Teaching and Reform of the Course of English Academic Thesis Writing. Education Teaching Forum, 15, 259-260.

Xie, S., \& L, W. (2012). Comments on Frequent Problems in Thesis Defense Demonstration of Translation Major. China Electric Power Education, 32, 156-157.

Zhuo, W. (2016). On the Exploration in Graduation Thesis Writing of Translation Direction of English Major in Xiamen University Tan Kah Kee College. Journal of Language and Literature Studies, 10, 150-151.

\section{Copyrights}

Copyright for this article is retained by the author(s), with first publication rights granted to the journal.

This is an open-access article distributed under the terms and conditions of the Creative Commons Attribution license (http://creativecommons.org/licenses/by/4.0/). 